\title{
Chapter 6 \\ Delayed Recovery from Declines in the Population Densities and Species Richness of Intertidal Invertebrates Near Fukushima Daiichi Nuclear Power Plant
}

\author{
Toshihiro Horiguchi, Keita Kodama, Gen Kume, and Ik Joon Kang
}

\begin{abstract}
In June 2014, May and June 2015, and June 2016, we conducted quantitative quadrat surveys of sessile invertebrates at seven intertidal sites in Ibaraki, Fukushima, and Miyagi Prefectures, including the sites near Fukushima Daiichi Nuclear Power Plant (FNPP), to check whether species richness, population densities, and biomass had recovered from declines after the 2011 Tohoku earthquake, tsunami and nuclear disaster. Additionally, in April, July, August and September from 2012 to 2017, we monitored the population density and spawning behavior of rock shells (Thais clavigera) in the field near FNPP. Increases in species richness and population densities in the intertidal zone near FNPP were not found until at least 4-5 years had passed after the FNPP accident. Densities of and reproductive performance by T. clavigera populations near FNPP in 2017 remained below levels before the accident. Although invertebrate larval recruitment from remote areas to the intertidal zone near FNPP could have been expected, this was not clearly observed until 2016 at the earliest. Thus, it is possible that environmental factors inhibited invertebrate reproduction, recruitment or both in the intertidal zone near FNPP at least for 5 years.
\end{abstract}

Keywords Fukushima Daiichi Nuclear Power Plant · Intertidal biota · Species richness $\cdot$ Population decline $\cdot$ Population density $\cdot$ Recovery $\cdot$ Recruitment . Reproduction $\cdot$ Rock shell (Thais clavigera) $\cdot$ Sessile organisms

T. Horiguchi $(\bowtie) \cdot$ K. Kodama

National Institute for Environmental Studies, Tsukuba, Ibaraki, Japan

e-mail: thorigu@nies.go.jp

G. Kume

Kagoshima University, Kagoshima, Japan

I. J. Kang

Kyushu University, Fukuoka, Japan

(C) The Author(s) 2020 


\subsection{Introduction}

After the 2011 Tohoku earthquake $\left(M_{w}\right.$ 9.0) and tsunami on 11 March 2011(the Great East Japan Earthquake Disaster), three nuclear reactors melted down at Fukushima Daiichi Nuclear Power Plant (FNPP). Hydrogen explosions in reactor buildings resulted in the emission of hundreds of petabecquerels $(\mathrm{PBq})$ of radionuclides to the environment [1]. The amount of radionuclide leakage from the FNPP accident was about one-tenth of that released by the 1986 Chernobyl NPP accident in Ukraine, where the total release of radionuclides was estimated to be 5,300 PBq, excluding radioactive noble gases (e.g., krypton-85, xenon-137 etc) [1].

The Tokyo Electric Power Company (FNPP owner and operator, TEPCO) estimated that $500 \mathrm{PBq}$ of radioactive noble gases, $500 \mathrm{PBq}$ of iodine-131 $\left({ }^{131} \mathrm{I}\right), 10 \mathrm{PBq}$ of cesium-134 $\left({ }^{134} \mathrm{Cs}\right)$ and $10 \mathrm{PBq}$ of ${ }^{137} \mathrm{Cs}$ were released from FNPP to the atmosphere between March 12 and 31, 2011 [2] and that atmospheric fallout and direct leakage from the reactors released an additional $11 \mathrm{PBq}$ of ${ }^{131} \mathrm{I}, 3.5 \mathrm{PBq}$ of ${ }^{134} \mathrm{Cs}$ and 3.6 PBq of ${ }^{137} \mathrm{Cs}$ into the marine environment between March 26 and September 30, 2011 [3]. Meanwhile, total deposition of ${ }^{137} \mathrm{Cs}$ from the atmosphere onto the ocean surface is estimated to have been 5-15 PBq [4-8]. Estimates of direct ${ }^{137} \mathrm{Cs}$ leakage from FNPP into the sea range from 3 to $6 \mathrm{PBq}$ [5-13].

Four major sources released FNPP-derived radionuclides to the environment. In the order of decreasing magnitude, these were as follows:

1. The initial venting and explosive releases of gases and volatile radionuclides to the atmosphere, the largest and earliest source, which led to fallout on land and at sea.

2. Direct leakage of contaminated material, including radionuclides from the reactors to the sea during emergency cooling efforts at FNPP.

3. Ongoing radionuclide release via groundwater discharge.

4. Ongoing radionuclide release via river runoff.

Radionuclide releases via groundwater and river discharge were much smaller than the initial atmospheric fallout and the subsequent direct leakage [14].

Although transport models indicate that more than $80 \%$ of the atmospheric fallout derived from the FNPP accident would have been on the ocean surface, with the highest levels of deposition expected in coastal waters near FNPP. However, there are no atmospheric fallout data over the ocean to confirm this [14].

The severity of the FNPP accident raised concerns about contamination of aquatic organisms by radionuclides, in both freshwater and marine environments. By the end of March 2011, the Japanese government began to determine activity concentration of radionuclidess (i.e., $\gamma$-emitters) in aquatic organisms (i.e., fish and shellfish) to protect human consumers. The analytical results are available on the website of the Fisheries Agency of Japan [15]. In general, contamination of marine organisms by radioactive $\mathrm{Cs}$ is higher in demersal fish than in pelagic fish; radionuclide contamination levels in both demersal and pelagic fish collected off Fukushima Prefecture have been higher than those in similar fish collected off 
other prefectures [15]. The activity concentrations of radioactive Cs in fish tissue, however, have since decreased in most fish sampled from the region (e.g., Wada et al. [16]). Fishing operations in the Fukushima Prefecture region restarted on a trial basis in June 2012, and the areas and species targeted have gradually expanded since then [17].

Since the FNPP accident occurred, there have been many researches and activities in the marine environment, including coastal waters off Fukushima Prefecture, to analyze spatiotemporal changes in radionuclide activity concentration, to determine the final fate of the radionuclides introduced into seawater and to evaluate contamination levels in marine organisms. However, within $20 \mathrm{~km}$ of FNPP, there are few available data on the distribution and spatiotemporal changes of radionuclides emitted from FNPP and their possible ecological effects.

According to the literature, wildlife including invertebrates, is tolerant to varying degrees of $\gamma$-radiation; at 100-1000 mGy/day, some mortality can be expected in larvae and hatchlings of flatfish [18]. At 10-100 mGy/day, reduced reproductive success is observed in flatfish, and at $1-10 \mathrm{mGy} / \mathrm{day}$, reduced reproductive success due to reduced fertility is possible [18]. Invertebrates such as crabs are more tolerant of radiation than are flatfish [18]. Estimated acute lethal dose $\left(\mathrm{LD}_{50}\right)$ is $>100 \mathrm{~Gy}$ for marine invertebrates, 10-25 Gy for fishes, and 0.16 Gy for fish (salmonid) embryos [19]. Chronic exposure has yielded no-observed-adverse-effect dose rate of $10-30 \mathrm{mGy} / \mathrm{h}$ (= 240-720 mGy/day) for mortality and 3.2-17 $\mathrm{mGy} / \mathrm{h}$ (= $76.8-408 \mathrm{mGy} /$ day) for reproduction in snails, marine scallops, clams and crabs [19]. The no-observed-effect dose rate for fish reproduction is $1 \mathrm{mGy} / \mathrm{h}(=24 \mathrm{mGy} /$ day) [19]. The United Nations Scientific Committee on the Effects of Atomic Radiation (UNSCEAR) extensively analyzed the relevant data on the effect of radiation on the environment and on nonhuman biota [20,21], concluding that maximum dose rate of less than $400 \mu \mathrm{Gy} / \mathrm{h}(=9.6 \mathrm{mGy} /$ day $)$ to any individual aquatic organism would be unlikely to have any detrimental effects at the population level [22]. This is based on the knowledge that there is little consistent and substantial evidence for any effect on reproduction at dose rate of $<200 \mu \mathrm{Gy} / \mathrm{h}(=4.8 \mathrm{mGy} /$ day $)$ [23-25]. A generic dose rate of $10 \mu \mathrm{Gy} / \mathrm{h}(=240 \mu \mathrm{Gy} /$ day $)$ is suggested for use in screening out environmental exposure situations of negligible concern [25-27].

On the other hand, anaseismic effects and the effect of tsunami backwash on the coastal organisms of eastern Japan have been estimated to be large or serious [28, 29]. The tsunami also caused the loss of tidal flats, as well as subsidence, temporary land elevation, and changes in sediment composition such as sludging or muddying, all of which had either direct or indirect impacts on the benthic organisms inhabiting the coastal areas [30]. The impacts of the tsunami on coastal benthic organisms, and the severity of these impacts, vary among species and sites [28, 29]. Temporary population declines have been observed in the Manila clam (Ruditapes philippinarum) in Matsukawaura, Fukushima Prefecture, although no effects on distribution have been observed in the bivalve Gomphina melanegis in Otsuchi Bay, Iwate Prefecture [31, 32]. The tsunami also affected reef resources, including abalone and sea urchins, through loss or reduction of seaweed forests as well as through direct 
impacts, though in Miyagi and Iwate Prefectures, the populations of some of these species have been observed to recover [32, 33].

Although dose rate from the environmental exposure in intertidal invertebrates near FNPP after the accident has not yet been estimated, Horiguchi et al. [34] investigated the intertidal zone from Shirahama (Chiba Prefecture) to Kuji (Iwate Prefecture) along the coastline of eastern Japan (a total distance of ca. $800 \mathrm{~km}$ ) in 2011, 2012 and 2013 to evaluate the ecological effect of the FNPP accident that accompanied the Great East Japan Earthquake Disaster. They observed that the number of intertidal species decreased significantly with proximity to FNPP and that no rock shell (Thais clavigera) specimens were collected near FNPP, from Hirono to Futaba Beach (a distance of approximately $30 \mathrm{~km}$ ) in 2012. The collection of rock shell specimens at many other sites hit by the tsunami suggested that the absence of rock shells around FNPP in 2012 might have been caused by the FNPP accident in 2011. Quantitative surveys in 2013 showed that the number of species and population densities in the intertidal zones were much lower at sites near or within several kilometers south of FNPP than at other sites and lower than in 1995, especially in the case of Arthropoda. There is no clear explanation for these findings, but evidently, the intertidal biota around FNPP has been harmed since the nuclear accident [34].

In June 2014, May and June 2015, and June 2016, we conducted quantitative quadrat surveys of sessile invertebrates at seven intertidal sites previously surveyed in Ibaraki, Fukushima and Miyagi Prefectures including sites near FNPP, to evaluate whether the intertidal invertebrates had recovered from the declines that followed the accident; we measured population densities (i.e., abundance, as indicated by the number of individuals per square meter), biomass (total wet weight of invertebrates per square meter) and species numbers. Additionally, in April, July, August, and September from 2012 to 2017, we monitored the density of rock shell (T. clavigera) populations and counted their egg capsules in the field near FNPP.

\subsection{Materials and Methods}

On June 13-16 and 26-28, 2014, May 18-21 and June 17-19, 2015, June 4-7, 21, 23 and 24, 2016, quantitative quadrat surveys of sessile invertebrates were conducted at seven sites: Tomioka Fishing Port (Tomioka Town; shown as Tomioka in Figs. 6.1b, 6.2, 6.3, 6.4, 6.5, 6.6 and 6.7), Ottozawa coast (Okuma Town; shown as Okuma in Figs. 6.1b, 6.2, 6.3, 6.4, 6.5, 6.6 and 6.7), Kubo-yaji coast (Futaba Town; shown as Kuboyaji in Figs. 6.1b, 6.2, 6.3, 6.4, 6.5, 6.6 and 6.7) and Urajiri coast (Minami-Soma City; shown as Urajiri in Figs. 6.1b, 6.2, 6.3, 6.4, 6.5, 6.6 and 6.7) in Fukushima Prefecture within a 20-km radius of FNPP; Hasaki Beach (Kamisu City) and Kujihama Beach (Hitachi City) in Ibaraki Prefecture; and Watanoha coast (Ishinomaki City; shown as Ishinomaki in Figs. 6.1b, 6.2, 6.3, 6.4, 6.5, 6.6 and 6.7) in Miyagi Prefecture as reference sites for comparison (Fig. 6.1b and Table 6.1). These sites were the same as those surveyed in 2013 and were representative of 


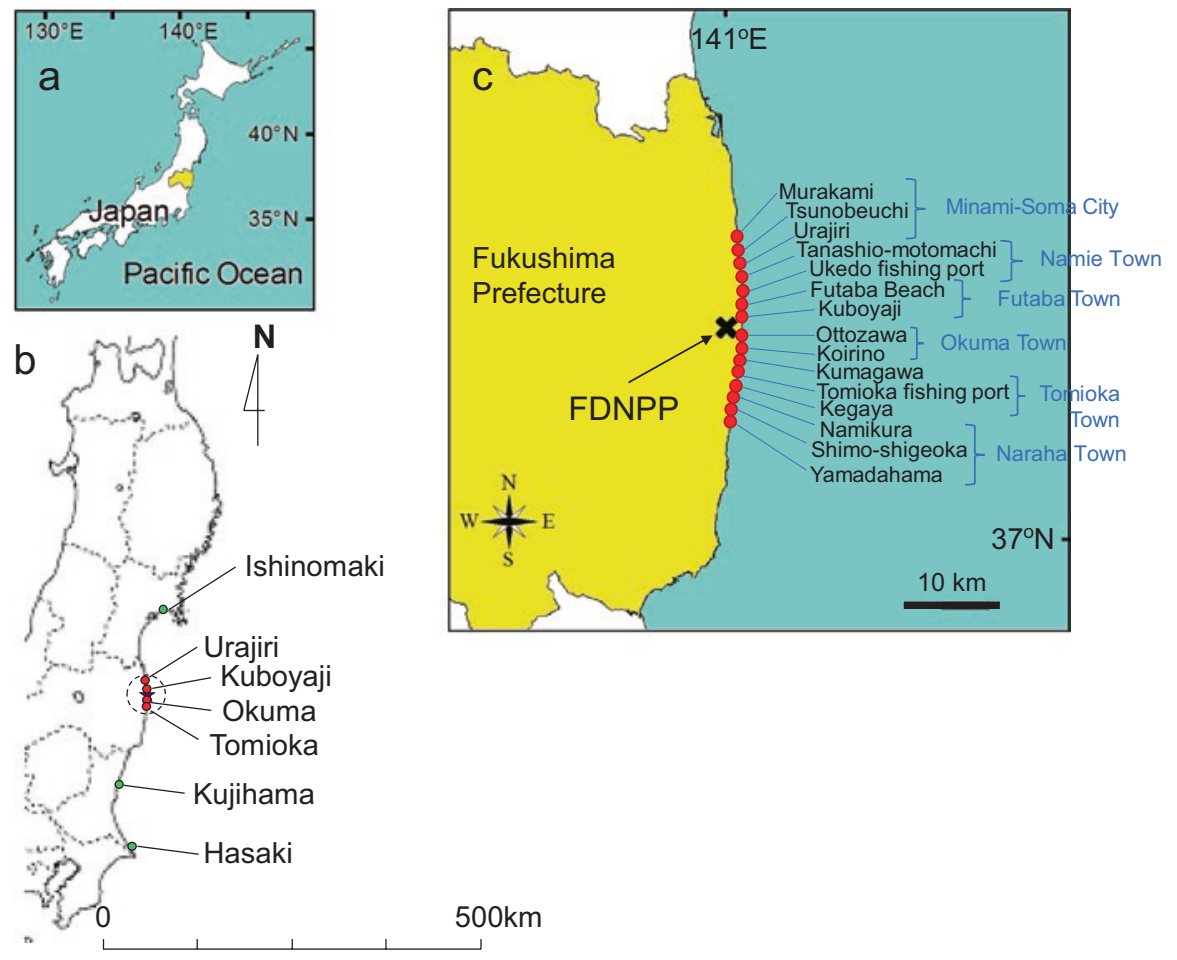

Fig. 6.1 Sampling sites of intertidal invertebrates during surveys from 2012 to 2017. (a) A map of Japan, where Fukushima Prefecture is marked in yellow. (b) Locations for sampling intertidal invertebrates during surveys in 2014, 2015 and 2016. Purple star marks the location of Fukushima Daiichi Nuclear Power Plant (FNPP). Dashed circle on map indicates a radius of $20 \mathrm{~km}$ from FNPP. Red dots on map indicate sites located within the 20-km radius of FNPP. (c) Site locations for surveys on density and spawning behavior of Thais clavigera populations from 2012 to 2017. FNPP is located between Ottozawa and Kubo-yaji

*The partial map of Japan in this figure (b) was modified by the authors from the map of Japan at the following website: http://www.freemap.jp/item/japan/japan1.html

those used in the 2012 surveys in terms of substrate (i.e., tetrapods or similar concrete structures set along the coast for wave protection) as well as distance from FNPP [34]. Sessile organisms on the surface of tetrapods or similar concrete structures within a $50 \times 50-\mathrm{cm}$ quadrat were collected at three different elevations in the intertidal zone (the lower, middle and upper intertidal zones) at each site. Specimens were preserved in neutral buffered $10 \%$ formalin solution. After identifying the species, the number of individuals and wet weight were determined for each species on the spot, along with the sampling location and elevation. Additionally, we conducted field observations on the density and spawning behavior of T. clavigera populations near FNPP in April, July, August and September from 2012 to 2017 (Fig. 6.1c and Table 6.2). The density of T. clavigera populations was expressed by the number of individuals collected per minute, because it was difficult to quantitatively represent 
a

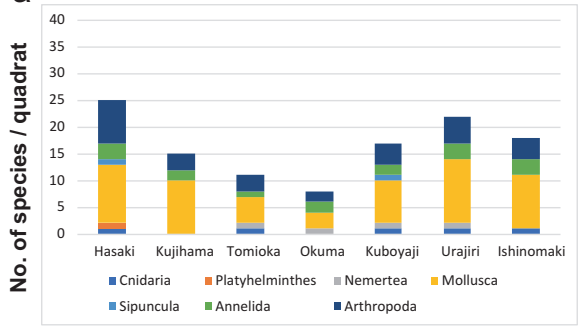

C

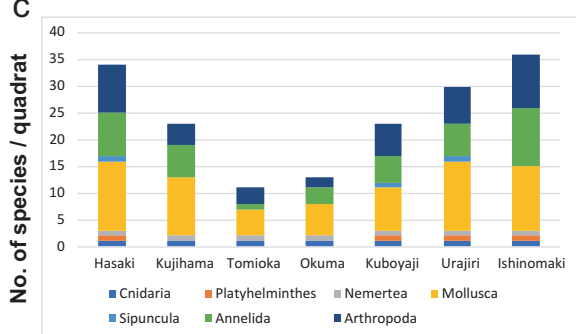

b

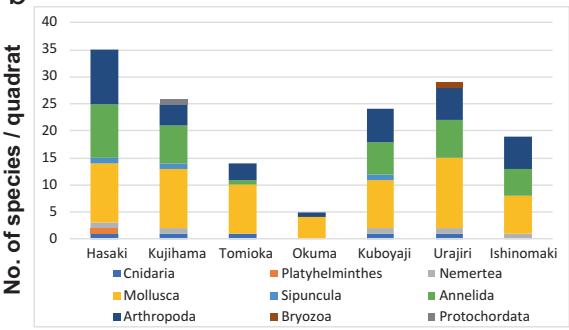

d

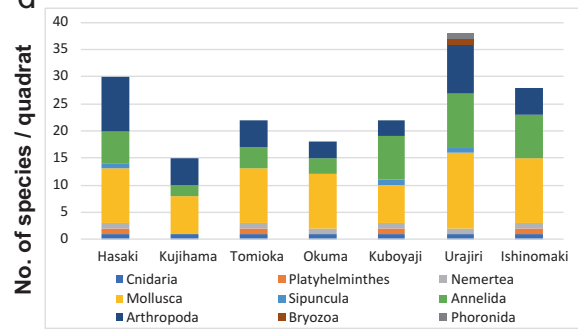

Fig. 6.2 Total numbers of sessile invertebrate species in the intertidal zone of seven sites from 2013 to 2016, as sampled with a $50 \times 50$-cm quadrat. (a) 2013, (b) 2014, (c) 2015 and (d) 2016. FNPP is located between Okuma and Kubo-yaji. Tomioka, Okuma, Kubo-yaji and Urajiri are located within the 20-km radius of FNPP. Distances between sites do not correspond to bar locations on the charts

a

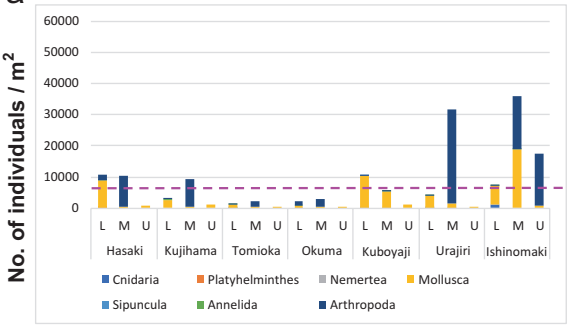

C

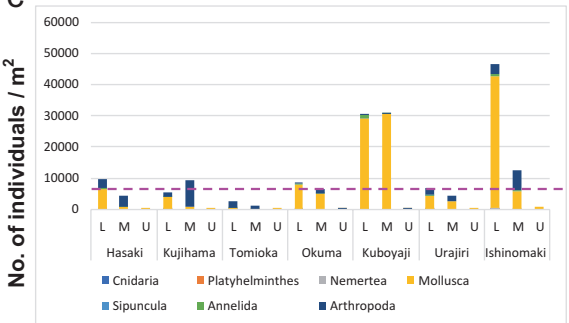

b

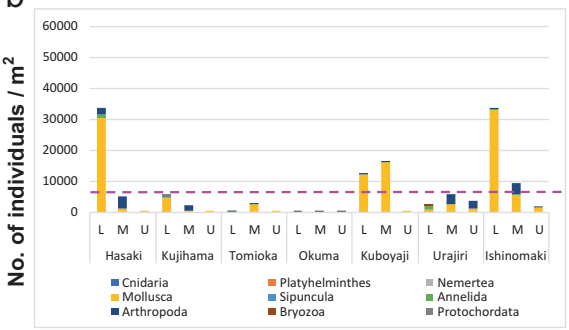

d

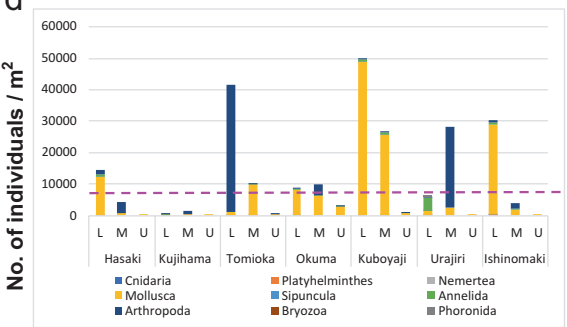

Fig. 6.3 Densities of sessile invertebrates (number $/ \mathrm{m}^{2}$ ) in the intertidal zone (by elevation) from 2013 to 2016. (a) 2013, (b) 2014, (c) 2015 and (d) 2016. L lower intertidal zone, $M$ middle intertidal zone, $U$ upper intertidal zone. Data were collected with a $50 \times 50-\mathrm{cm}$ quadrat. FNPP is located between Okuma and Kubo-yaji. Tomioka, Okuma, Kubo-yaji and Urajiri are located within the 20-km radius of FNPP. Distances between sites do not correspond to bar locations on the charts. Pink dotted line represents the average number of individuals $/ \mathrm{m}^{2}$ from quadrat surveys of sessile organisms conducted in May 1995 at 20 sites along the coast of Fukushima Prefecture [37]: the average population density in 1995 was 7,158 individuals $/ \mathrm{m}^{2}$, consisting of Arthropoda (4593, 64.2\%), Annelida (179, 2.5\%), Mollusca $(2348,32.8 \%)$ and other organisms $(38,0.5 \%)$ 
a

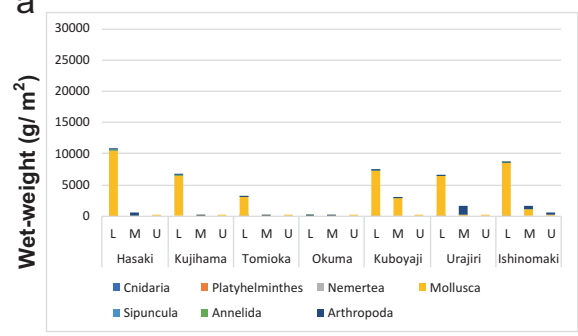

C

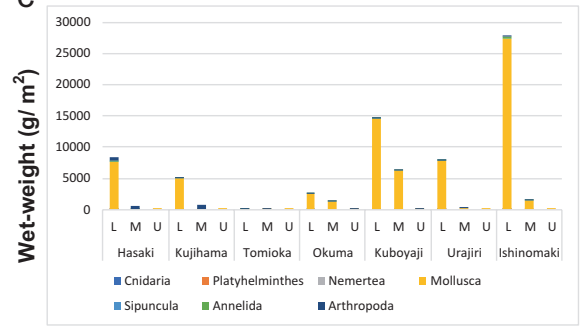

b

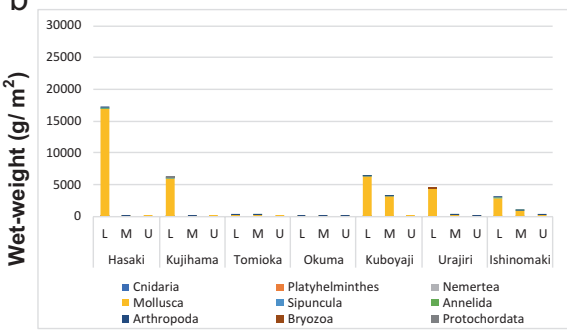

d

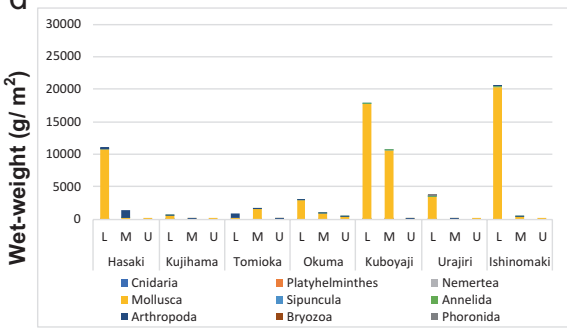

Fig. 6.4 Total biomass (wet weight, $\mathrm{g} / \mathrm{m}^{2}$ ) of sessile invertebrates in the intertidal zone (by elevation) from 2013 to 2016. (a) 2013, (b) 2014, (c) 2015 and (d) 2016. L lower intertidal zone, $M$ middle intertidal zone, $U$ upper intertidal zone. Data were collected with a $50 \times 50$-cm quadrat. FNPP is located between Okuma and Kubo-yaji. Tomioka, Okuma, Kubo-yaji and Urajiri are located within the 20-km radius of FNPP. Distances between sites do not correspond to bar locations on the charts

the area where T. clavigera specimens were collected at different forms of tetrapods or concrete structures for wave protection.

To assess similarity in the biotic community structure of the intertidal zone in the survey from 2014 to 2016, we conducted cluster analysis (group average method) on Bray-Curtis similarity matrices for the number of species, population density (the number of individuals $/ \mathrm{m}^{2}$ ) and total sessile biomass (whole wet weight per square meter, $\mathrm{g} / \mathrm{m}^{2}$ ). Population density data from the lower, middle, and upper intertidal zones were merged within each site, and $\log (1+x)$ transformed for calculation of Bray-Curtis similarity. Site grouping was performed with a cut-off similarity level of 70 or $80 \%$. Differences in the biotic community structure represented by Bray-Curtis similarity among site groups [35] were tested by analysis of similarity (ANOSIM). Possible differences in population densities of Arthropoda (i.e., the number of individuals $/ \mathrm{m}^{2}$ ) at sites near FNPP (i.e., Tomioka, Okuma, and Kuboyaji) compared to those at other sites (i.e., Hasaki, Kujihama, Urajiri, and Ishinomaki) were evaluated using a t-test under the assumption that they had approximately equal variances each year. Statistical analyses (t-test) were performed with Microsoft Excel 2016 statistical software, except for cluster analysis and ANOSIM, which were conducted with PRIMER6 software [36]. 

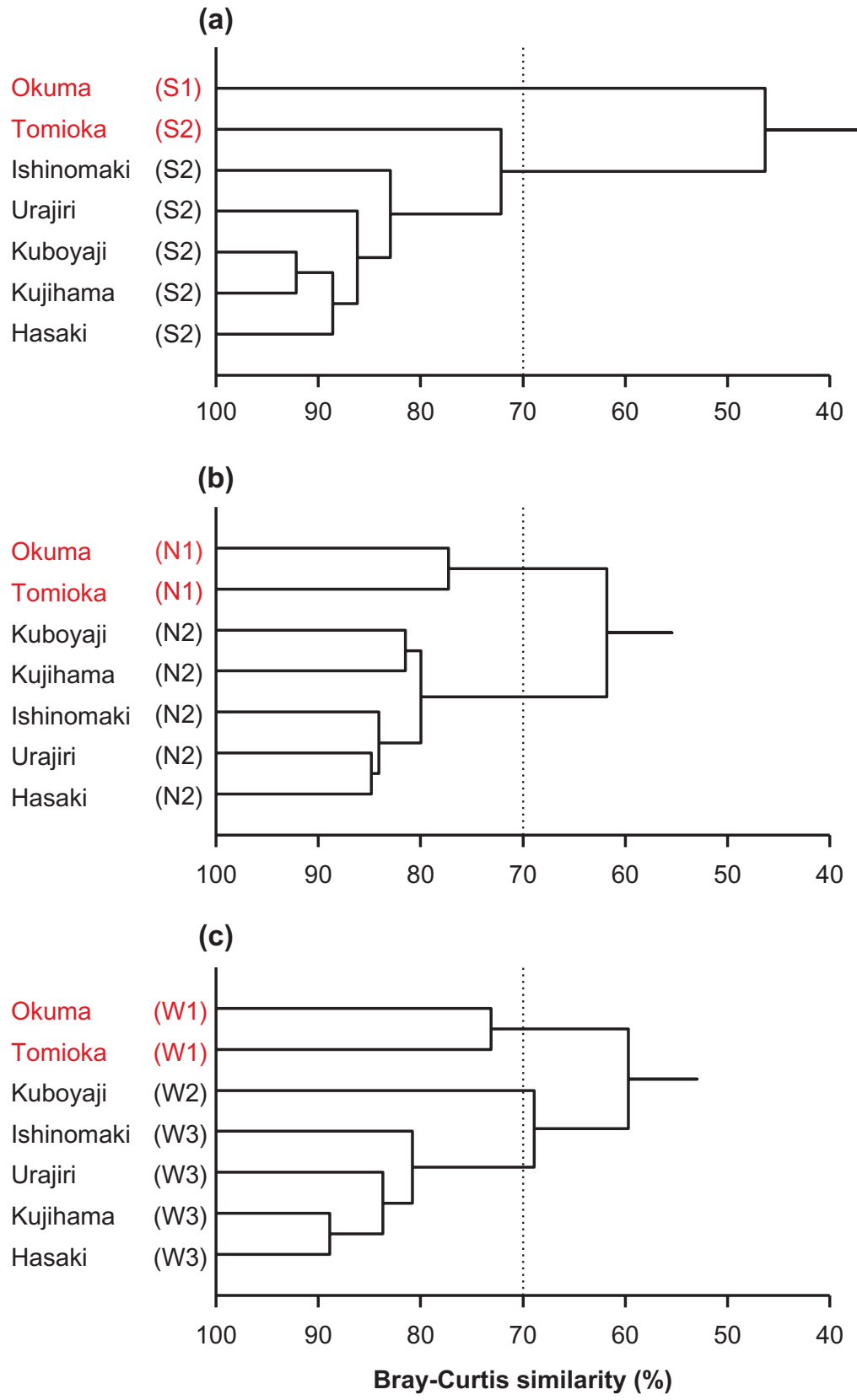

Fig. 6.5 Dendrograms constructed by the group average method on Bray-Curtis similarity matrices for (a) number of species, (b) population density, and (c) total biomass of intertidal invertebrates collected in northeastern Japan on June 13-16 and 26-28, 2014. Population density data from the lower, middle, and upper intertidal zones were merged within each site, and log $(1+\mathrm{x})$ transformed for calculation of Bray-Curtis similarity. Site groupings based on cut-off similarity level of 70\% (dotted lines) are shown as S1-S2, N1-N2, and W1-W3 for panels (a), (b), and (c), respectively. The two sites (Okuma and Tomioka) located south of FNPP are shown in red text 


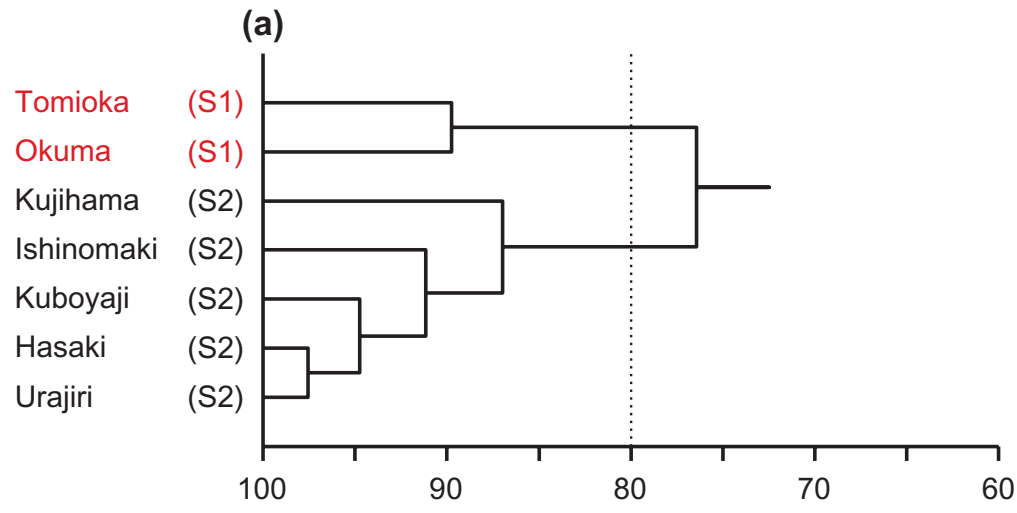

(b)

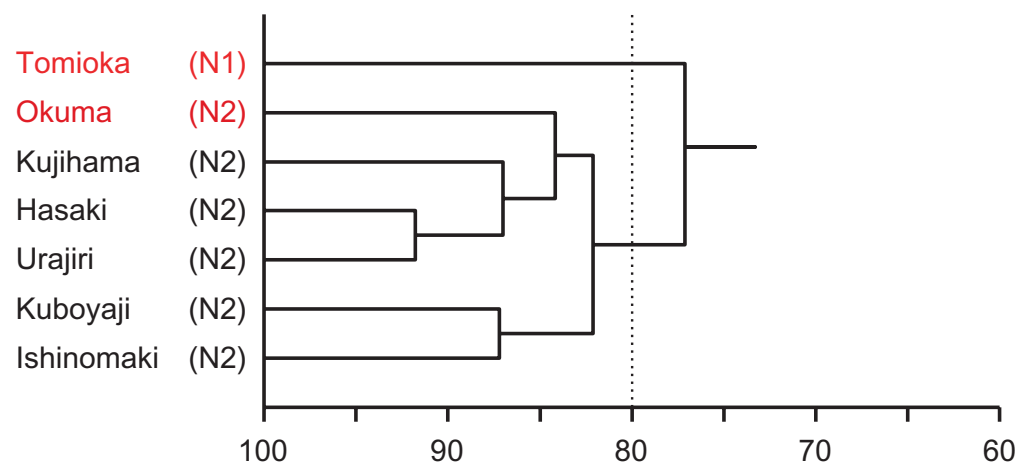

(c)

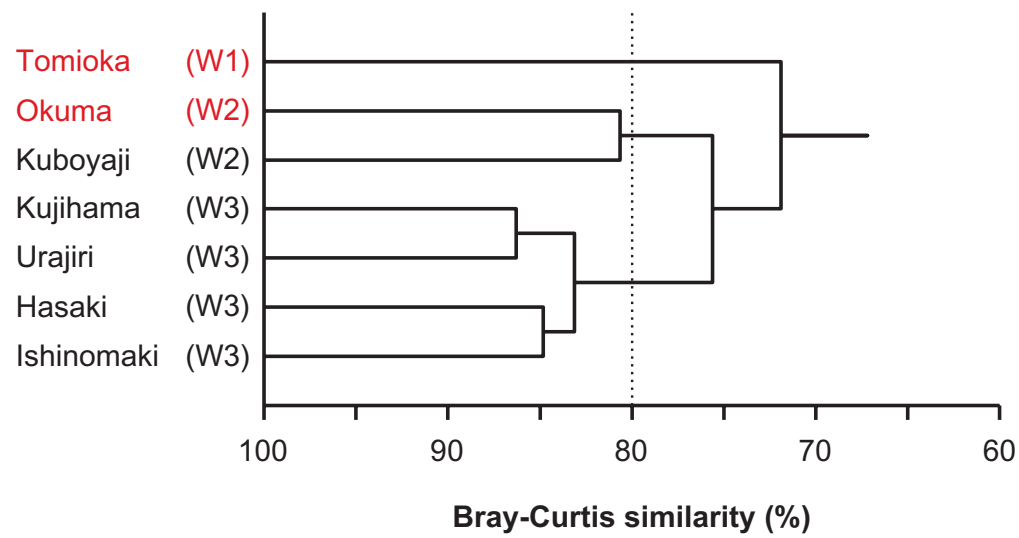

Fig. 6.6 Dendrograms constructed by the group average method on Bray-Curtis similarity matrices for (a) number of species, (b) population density, and (c) total biomass of intertidal invertebrates collected in northeastern Japan on May 18-21 and June 17-19, 2015. Population density data from lower, middle, and upper intertidal zones were merged within each site, and log $(1+\mathrm{x})$ transformed for calculation of Bray-Curtis similarity. Site groupings based on cut-off similarity level of $80 \%$ (dotted lines) are shown as S1-S2, N1-N2, and W1-W3 for panels (a), (b), and (c), respectively. The two sites (Okuma and Tomioka) located south of FNPP are shown in red text 


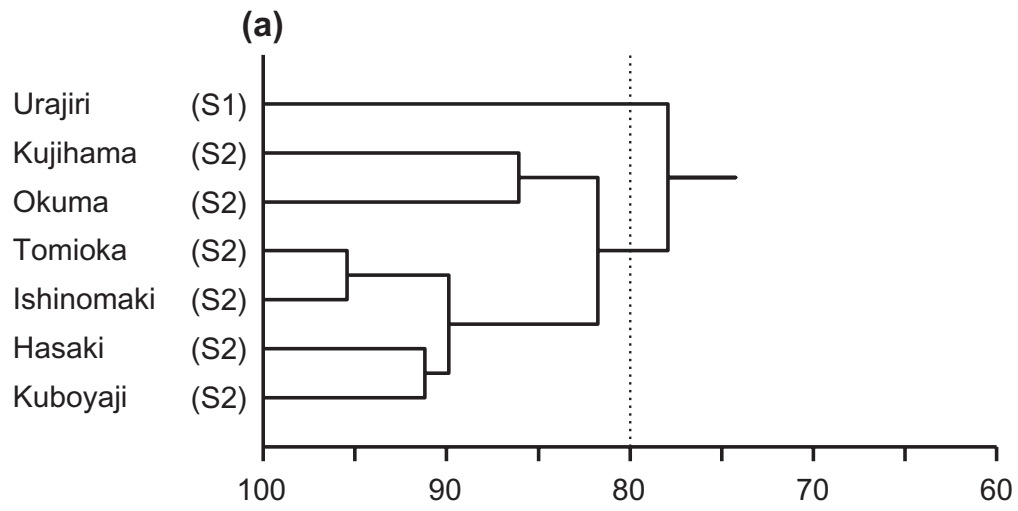

(b)

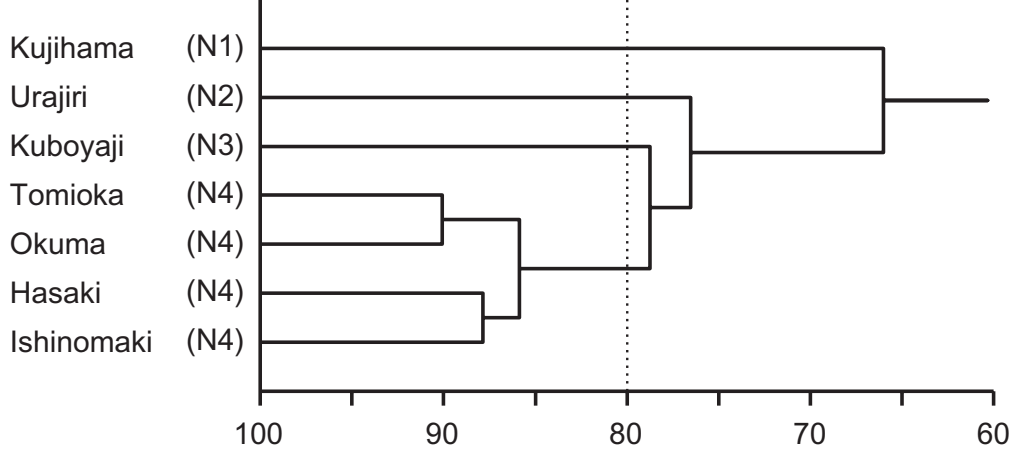

(c)

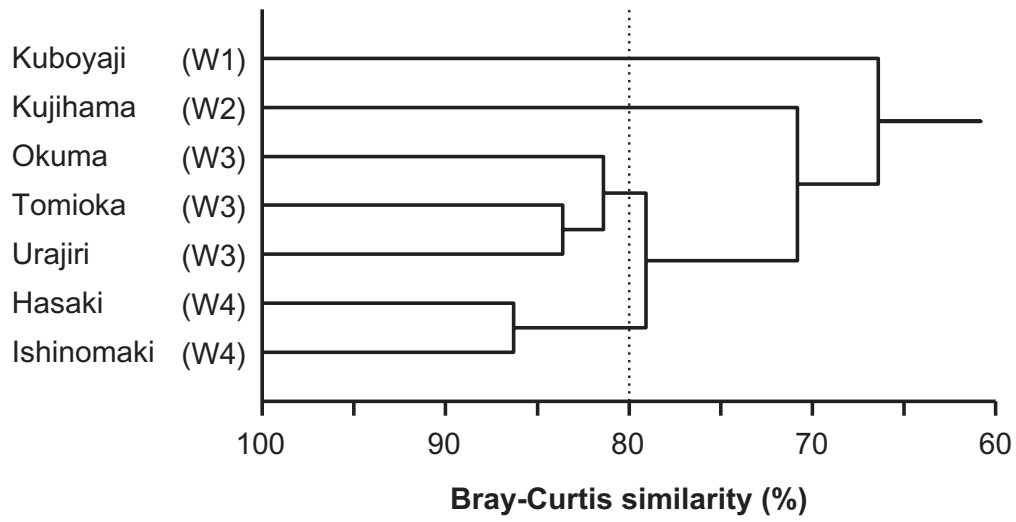

Fig. 6.7 Dendrograms constructed by the group average method on Bray-Curtis similarity matrices for (a) number of species, (b) population density, and (c) total biomass of intertidal invertebrates collected in northeastern Japan on June 4-7, 21, 23 and 24, 2016. Population density data from the lower, middle, and upper intertidal zones were merged within each site, and $\log (1+\mathrm{x})$ transformed for calculation of Bray-Curtis similarity. Site groupings based on cut-off similarity level of $80 \%$ (dotted lines) are shown as S1-S2, N1-N4, and W1-W4 for panels (a), (b), and (c), respectively 
Table 6.1 Locations for sampling intertidal invertebrates during surveys in 2014, 2015 and 2016

\begin{tabular}{|c|c|c|c|c|c|c|c|}
\hline 2016 & 2015 & 2014 & \multicolumn{5}{|c|}{ Sampling location } \\
\hline Date & Date & Date & Prefecture & City/Town & Name of site & Latitude & Longitude \\
\hline 21-Jun & 19-Jun & 28-Jun & Ibaraki & Kamisu City & Hasaki Beach & $35^{\circ} 45^{\prime} 14.8^{\prime \prime} \mathrm{N}$ & $140^{\circ} 50^{\prime} 16.3^{\prime \prime} \mathrm{E}$ \\
\hline 23-Jun & 17-Jun & 26-Jun & Ibaraki & Hitachi City & Kujihama Beach & $36^{\circ} 30^{\prime} 09.8^{\prime \prime} \mathrm{N}$ & $140^{\circ} 37^{\prime} 48.0^{\prime \prime} \mathrm{E}$ \\
\hline 6-Jun & 20-May & 14-Jun & Fukushima & Tomioka Town & Tomioka Fishing Port & $37^{\circ} 20^{\prime} 16.3^{\prime \prime} \mathrm{N}$ & $141^{\circ} 01^{\prime} 45.3^{\prime \prime} \mathrm{E}$ \\
\hline 4-Jun & 19-May & 13-Jun & Fukushima & Okuma Town & Ottozawa coast & $37^{\circ} 24^{\prime} 21.2^{\prime \prime} \mathrm{N}$ & $141^{\circ} 02^{\prime} 00.4^{\prime \prime} \mathrm{E}$ \\
\hline 5-Jun & 18-May & 15-Jun & Fukushima & Futaba Town & Kubo-yaji coast & $37^{\circ} 26^{\prime} 41.4^{\prime \prime} \mathrm{N}$ & $141^{\circ} 02^{\prime} 10.9^{\prime \prime} \mathrm{E}$ \\
\hline 7-Jun & 21-May & 16-Jun & Fukushima & Minami-Soma City & Urajiri coast & $37^{\circ} 31^{\prime} 33.7^{\prime \prime} \mathrm{N}$ & $141^{\circ} 01^{\prime} 53.8^{\prime \prime} \mathrm{E}$ \\
\hline & & 27-Jun & Miyagi & Ishinomaki City & Watanoha coast & $38^{\circ} 24^{\prime} 50.8^{\prime \prime} \mathrm{N}$ & $141^{\circ} 21^{\prime} 28.1^{\prime \prime} \mathrm{E}$ \\
\hline & 18-Jun & & Miyagi & Ishinomaki City & Watanoha coast & $38^{\circ} 24^{\prime} 48.4^{\prime \prime} \mathrm{N}$ & $141^{\circ} 21^{\prime} 31.6^{\prime \prime} \mathrm{E}$ \\
\hline 24-Jun & & & Miyagi & Ishinomaki City & Watanoha coast & $38^{\circ} 24^{\prime} 47.4^{\prime \prime} \mathrm{N}$ & $141^{\circ} 21^{\prime} 35.0^{\prime \prime} \mathrm{E}$ \\
\hline
\end{tabular}

Fukushima Daiichi Nuclear Power Plant (FNPP) is located between Ottozawa and Kubo-yaji. Red text indicates sites within a $20-\mathrm{km}$ radius of FNPP. We had to change the location at Watanoha, Ishinomaki a little every year, because of the restoration work of coastal structures

\subsection{Results}

In the intertidal zone at all sites surveyed from 2014 to 2016, the sessile species composition was dominated by the Mollusca and Arthropoda, followed by Annelida, similar to the 2013 results [34] (Fig. 6.2). The maximum number of intertidal species in 2014 was 35 at Hasaki, followed by 29 at Urajiri. The minimum of five species was at Okuma, located approximately $1 \mathrm{~km}$ south of FNPP (Fig. 6.2b). However, the similarity in species number between Tomioka and Okuma, both of which are located south of FNPP, was not very high and did not significantly differ from that between other sites in 2014, as determined by analysis of similarity (ANOSIM) of the biotic community structure represented by Bray-Curtis similarity among site groups [35] ( $P=0.14$; Figs. 6.2b and 6.5a). This result differed from that of the 2013 survey. The pattern of more species being identified in 2014 at Hasaki, Kujihama, Kubo-yaji, Urajiri and Ishinomaki than at Tomioka and Okuma was also observed in 2015 (Fig. 6.2c). The similarity in species number between Tomioka and Okuma, south of FNPP, was high and differed significantly from that between other sites in 2015 ( $P<0.05$; Figs. 6.2c and 6.6a). In 2016, however, no such pattern of more species being identified at Hasaki, Kujihama, Kubo-yaji, Urajiri and Ishinomaki than at Tomioka and Okuma was observed, due to an increase in the number of species at Tomioka and Okuma (Fig. 6.2d). The similarity in species number between Tomioka and Okuma, located south of FNPP, was not very high and differed insignificantly from that between other sites in $2016(P=0.29$; Figs. 6.2d and 6.7a).

Population densities were higher in the lower and middle intertidal zones than in the upper intertidal zone at all sites surveyed from 2014 to 2016 (Fig. 6.3b-d), which is similar to the 2013 results [34]. Mollusca (e.g., mussels such as Mytilus galloprovincialis and Septifer virgatus) and Arthropoda (e.g., barnacles such as 


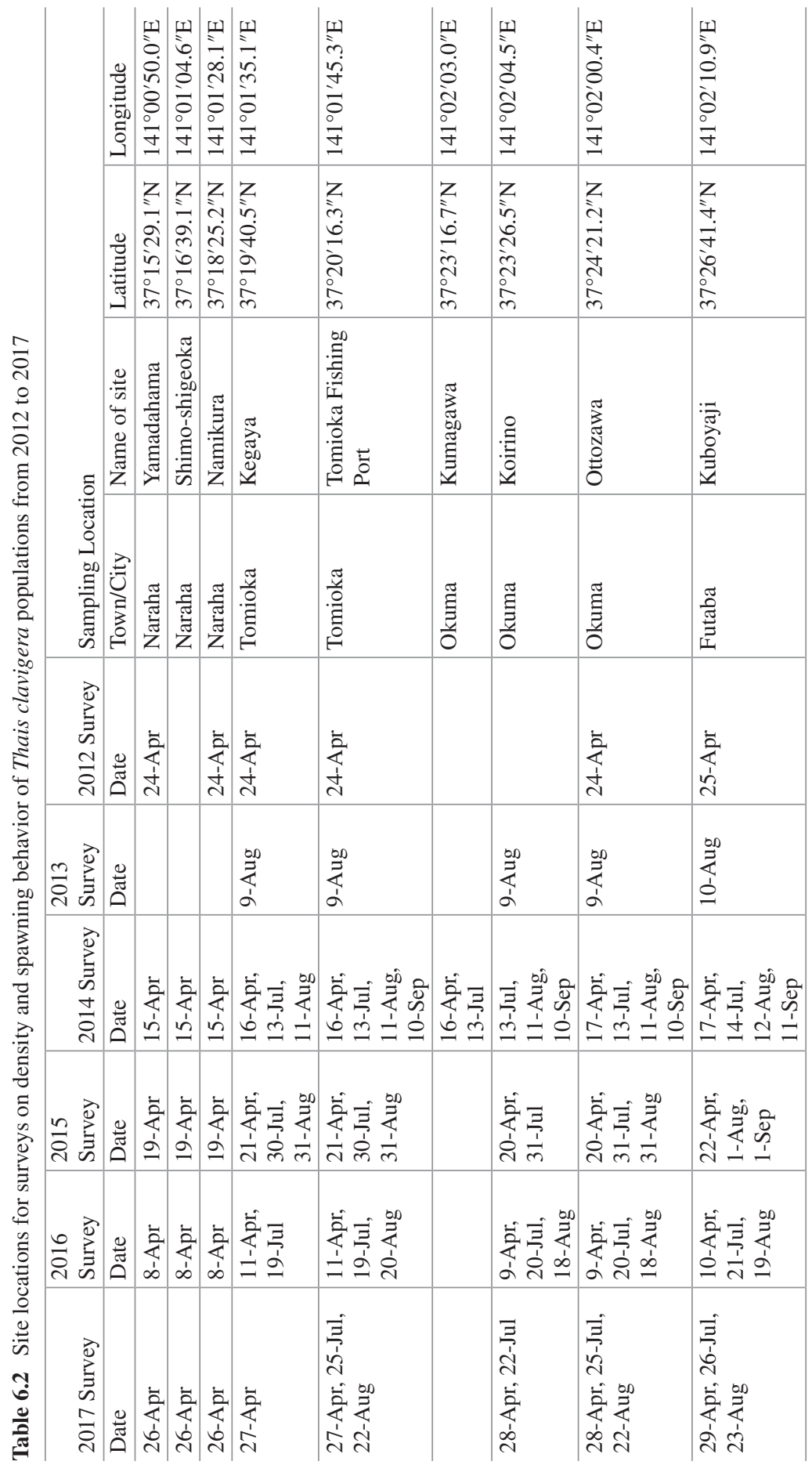




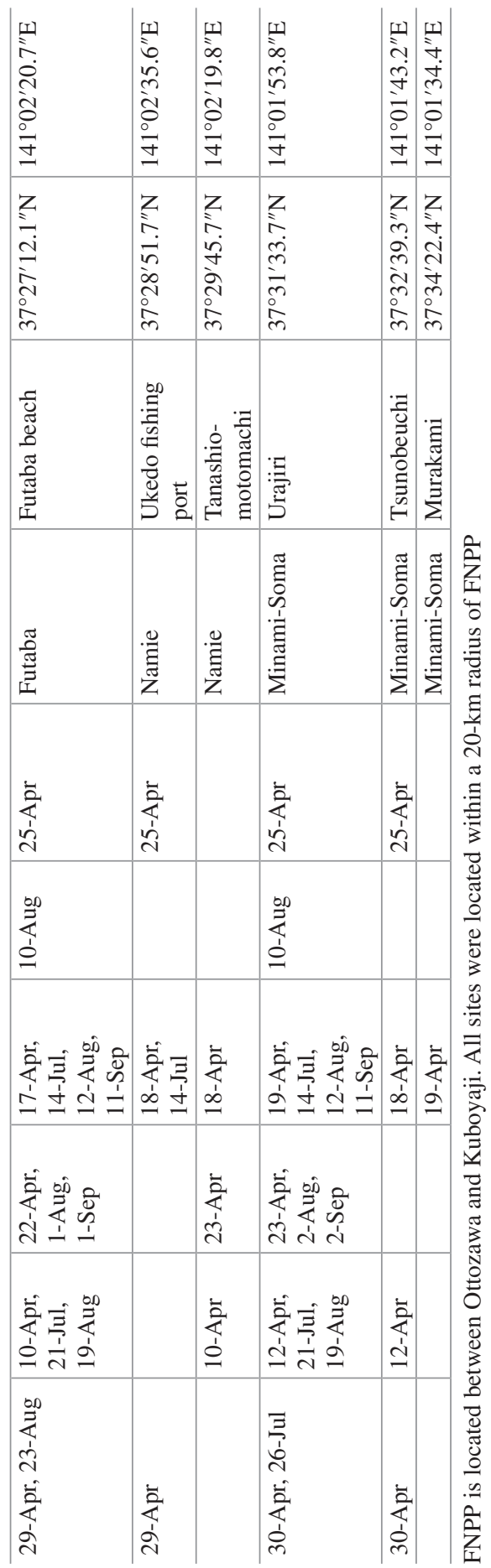


Chthamalus challengeri) predominated at almost all sites surveyed. Species composition in 2014 was highly similar between Tomioka and Okuma, both located south of FNPP $(P<0.05$; Figs. 6.3b and 6.5b), but not in $2015(P=0.14$; Figs. $6.3 \mathrm{c}$ and 6.6b). In 2016, the species composition at Kujihama, Urajiri and Kubo-yaji differed significantly from that at the other sites (Tomioka, Okuma, Hasaki and Ishinomaki) $(P<0.05$; Figs. $6.3 \mathrm{~d}$ and $6.7 \mathrm{~b})$, but not from those at sites south of FNPP (i.e., Tomioka and Okuma), although it was one of typical characteristics in the 2013 survey that population densities in the intertidal zone were significantly lower at sites south of FNPP than at other sites [34].

From 2014 to 2016, the population density of sessile organisms at Kubo-yaji, approximately $1 \mathrm{~km}$ north of FNPP, was greater than those at Kujihama and Urajiri (Fig. 6.3b-d). However, the species composition of sessile organisms at Kubo-yaji differed markedly from those at other sites surveyed in that the Arthropoda accounted for less than $1 \%$ of all sessile organisms collected (Fig. 6.3b-d), which is similar to the 2013 survey [34]. Population densities of Arthropoda at sites near FNPP (Tomioka, Okuma, and Kubo-yaji) were significantly lower than those at other sites in 2014 and 2015 ( $t$-test; $P<0.05)$, but not in $2016(P=0.66)$.

The combined wet weight of all sessile organisms from 2014 to 2016 was the greatest in the lower intertidal zone at almost all sites, followed by the middle and upper intertidal zone (Fig. 6.4b-d), similar to the results in 2013 [34]. From 2014 to 2016, molluscan biomass predominated at all surveyed sites, followed by arthropodan biomass (Fig. 6.4b-d). Species composition at Tomioka was similar to that at Okuma and differed significantly from that at other sites in 2014 and 2015 $(P<0.05$; Figs. 6.4b, c, 6.5c, and 6.6c). In 2016, however, there was a significant difference of similarity in the species composition between the occurrences at Kubo-yaji, Kujihama, most central Fukushima sites (Okuma, Tomioka, and Urajiri), and the sites at both ends of the survey (Hasaki and Ishinomaki) $(P<0.05$; Figs. $6.4 \mathrm{~d}$ and 6.7c), but not in the south of FNPP (i.e., Tomioka and Okuma), which was one of the typical characteristics observed in the 2013 survey: total sessile biomass in the intertidal zone were significantly lower at sites south of FNPP than at other sites in the 2013 survey [34].

The distribution of rock shells (T. clavigera) near FNPP gradually expanded from sites in north (Minami-Soma City and Namie Town Fig. 6.8a, b, respectively) and south (Naraha Town and Tomioka Town Fig. 6.8f, e, respectively) to sites in central Fukushima (Futaba Town and Okuma Town Fig. 6.8c, d, respectively). Densities also seemed to increase from 2012 to 2016, with large variations (Fig. 6.8). When we started the field survey in December 2011, 9 months after the FNPP accident, T. clavigera had disappeared from Ottozawa, Okuma Town, approximately $1 \mathrm{~km}$ south of FNPP; they remained absent until July 2016: the first record on the density of T. clavigera population at Ottozawa, Okuma Town, in July 2016 was 0.03 individuals collected per minute (i.e., 3 individuals collected within $90 \mathrm{~min}$ ). Consequently, the gap in the distribution of $T$. clavigera along the Fukushima coast seems to have closed by July 2016. However, population densities have remained low (around or less than 1 individual collected per minute) at 


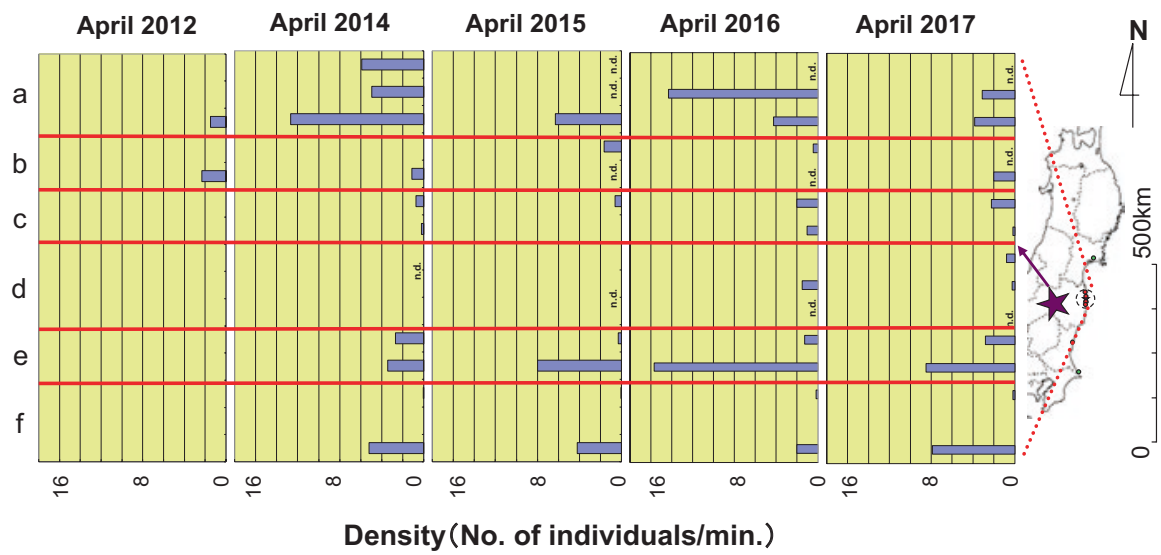

Fig. 6.8 Population densities (number/minute) of the rock shell (Thais clavigera) at 15 sites along the coast of Fukushima Prefecture from April 2012 to April 2017. Purple star marks the location of FNPP. Dashed circle on map indicates a radius of $20 \mathrm{~km}$ from FNPP. Red dots on map indicate sites located within the 20-km radius of FNPP. (a) Minami-Soma City, (b) Namie Town, (c) Futaba Town, (d) Okuma Town, (e) Tomioka Town, and (f) Naraha Town. $n . d$. no data *The partial map of Japan in this figure was modified by the authors from the map of Japan at the following website: http://www.freemap.jp/item/japan/japan1.html

Table 6.3 Egg capsules in Thais clavigera populations at sites near FNPP

\begin{tabular}{l|l|l|l|l|l|l}
\hline Location & Distance from FDNPP $(\mathrm{km})$ & 2013 & 2014 & 2015 & 2016 & 2017 \\
\hline Minami-Soma A (Urajiri) & 17.5 & ++ & +++ & - & +++ & +++ \\
\hline Futaba B (Beach) & 3.5 & - & - & ++ & - & +++ \\
\hline Futaba A (Kubo-yaji) & 1.5 & - & - & - & - & + \\
\hline Okuma (Ottozawa) & 1.2 & - & - & - & - & ++ \\
\hline Okuma (Koirino) & 3.6 & - & - & - & - & ++ \\
\hline Tomioka B (Fishing port) & 9.5 & - & - & - & - & - \\
\hline Tomioka A (Kegaya) & 10.5 & - & + & - & n.s. & n.s. \\
\hline
\end{tabular}

$+++:>100 \mathrm{~cm}^{2}$ of the total areas where egg capsules were spawned

$++: 5-100 \mathrm{~cm}^{2}$ of the total areas where egg capsules were spawned

$+:<5 \mathrm{~cm}^{2}$ of the total areas where egg capsules were spawned

-: no egg capsules observed

n.s. not surveyed

The names of locations are expressed as in [34]

sites in Okuma Town, within a few kilometers south of FNPP (Fig. 6.8d). Moreover, neither spawning behavior nor egg capsules were observed in populations at sites near FNPP (from Tomioka Fishing Port to Kubo-yaji) through the summer of 2016; egg capsules were first observed at Koirino, Ottozawa (Okuma Town) and Kuboyaji (Futaba Town) in the summer of 2017 (Table 6.3 and Fig. 6.1c). 


\subsection{Discussion}

In 2011, 2012 and 2013, Horiguchi et al. [34] investigated the ecological effect in the intertidal zone of eastern Japan affected by the FNPP accident that accompanied the Great East Japan Earthquake Disaster. They reported that the number of intertidal species decreased significantly with proximity to FNPP, and that no rock shell (T. clavigera) specimens were found near FNPP, from Hirono to Futaba Beach (a distance of approximately $30 \mathrm{~km}$ ) in 2012 . The presence of rock shell specimens at many other sites hit by the tsunami suggested that the absence of rock shells around FNPP in 2012 might have been caused by the FNPP accident. The quantitative 2013 surveys also showed that the number of species and population densities in the intertidal zones were much lower at sites near or within several kilometers south of FNPP than at other sites, and lower than in 1995, especially in the case of Arthropoda. There is no clear explanation for these findings. Although there are no estimates of radiation doses from environmental exposure in invertebrates in the intertidal zone near FNPP after the accident, clearly the intertidal biota around FNPP has been harmed since the nuclear accident.

The present study was carried out to investigate temporal changes in species composition and population densities in the intertidal zone of eastern Japan since 2014. Increases in species richness were evident at Tomioka Fishing Port (Tomioka) and Ottozawa (Okuma), which are located south of FNPP, from 2016, though this increase might have started at Ottozawa (Okuma) in 2015 (Fig. 6.2). Meanwhile, population densities have increased in the lower and middle intertidal zones at Ottozawa (Okuma) and Tomioka Fishing Port (Tomioka) since 2015 and 2016, respectively (Fig. 6.3). These increases were due to increases in small mussels (i.e., Mytilus galloprovincialis) at Ottozawa (Okuma) and barnacles (i.e., Semibalanus cariosus and Chthamalus challengeri) at Tomioka Fishing Port (Tomioka). In 1995, TEPCO conducted similar seasonal surveys using $30 \times 30-\mathrm{cm}$ quadrats at 20 sites in intertidal zone along the coast of Fukushima Prefecture, but only published a summary of their results [37]. In May 1995, they found an average of 7,158 individual sessile organisms $/ \mathrm{m}^{2}$, consisting of Arthropoda (4,593, 64.2\%), Annelida (179, $2.5 \%)$, Mollusca $(2348,32.8 \%)$, and other organisms $(38,0.5 \%)$ [37]; thus, although Arthropoda clearly predominated, many other invertebrates were also present in Fukushima Prefecture in 1995, before the FNPP accident. Compared with the TEPCO data, we observed similar or higher numbers of individuals $/ \mathrm{m}^{2}$ in the lower and middle intertidal zones at Ottozawa (Okuma) in 2015 and Tomioka Fishing Port (Tomioka) in 2016 (Fig. 6.3). Because of their small sizes, however, increases in the total biomass at Ottozawa (Okuma) in 2015 and Tomioka Fishing Port (Tomioka) in 2016 were unclear (Fig. 6.4).

The species composition of sessile organisms at Kubo-yaji, approximately $1 \mathrm{~km}$ north of FNPP, differed markedly from that at other sites surveyed, in that the Arthropoda accounted for less than $1 \%$ of all sessile organisms collected (Fig. 6.3b-d). Although Arthropoda predominated in the intertidal zone of Fukushima Prefecture in 1995 [37], population densities seem to have decreased 
after the FNPP accident. The reduced population densities there have continued since 2013. Population densities of Arthropoda at sites near FNPP (Tomioka, Okuma, and Kubo-yaji) were significantly lower than those at other sites in 2014 and 2015 ( $t$-test; $P<0.05)$, but not in $2016(P=0.66)$, possibly due to increases in barnacle population densities in the lower intertidal zone at Tomioka Fishing Port (Tomioka) in 2016 (Fig. 6.3d).

No T. clavigera specimens were observed near FNPP from Hirono to Futaba Beach (a distance of approximately $30 \mathrm{~km}$ ) in 2012 [34]. In the present study conducted during 2014-2017, however, their distribution gradually expanded year by year from sites in the north and south to sites along the central Fukushima coast (Fig. 6.8), and the gap in the distributions, where no T. clavigera specimens were found, had closed by July 2016, approximately a year after an observation of increases in small mussels (i.e., Mytilus galloprovincialis) at Ottozawa (Okuma) in 2015; these mussels are prey for T. clavigera (Fig. 6.3c). The increase in prey organisms, such as small mussels (i.e., Mytilus galloprovincialis) at Ottozawa (Okuma) in 2015 might have been associated with the first observation of T. clavigera specimens there in July 2016, since our field survey started in December 2011, 9 months after the FNPP accident. The densities of $T$. clavigera populations seemed to increase from 2012 to 2016, with large variations (Fig. 6.8). Low densities in T. clavigera populations (around or less than 1 individual collected per minute), however, have persisted at sites in Okuma Town, within a few kilometers south of FNPP (Fig. 6.8d). In general, population densities of T. clavigera in Japan range from 1 to 4 individuals collected per minute (Horiguchi et al., unpublished data). Neither spawning behavior nor egg capsules spawned by $T$. clavigera populations were observed at sites near FNPP (from Tomioka Fishing Port to Kubo-yaji) through the summer of 2016 (Table 6.3). Egg capsules were first observed at Koirino, Ottozawa (Okuma Town), and Kubo-yaji (Futaba Town) in the summer of 2017, though the number of egg capsules spawned was limited (Table 6.3).

The number of species and population densities in the intertidal zone near FNPP did not begin to increase until at least 4-5 years after the FNPP accident. Even in 2017, 6 years after the disaster, densities of and reproductive performance by T. clavigera populations near FNPP remained below pre-disaster levels. Most invertebrates in the intertidal zone, including sessile organisms, have planktonic stages in their early life histories for certain periods: for example, $T$. clavigera has a veliger larva that lives a few months before settling [38]. In the coastal waters off Fukushima Prefecture, the generally weak currents and tides [39] are expected to effect the dispersion of larvae of most invertebrates in the intertidal zone, as well as dispersion of FNPP-derived radioactive Cs. The Kuroshio and Oyashio currents, which are the wind-driven boundary currents of the North Pacific, meet in the Kuroshio-Oyashio transition area off FNPP [40]. The Kuroshio is part of the subtropical gyre and transports warm saline water along the south coast of Japan and then eastward via the Kuroshio Extension (KE), whereas the Oyashio is part of the subarctic gyre and transports cold less saline water southward [41]. Actually, results on the bottom-sediment survey collected from a coastal strip $(\sim 30 \times 120 \mathrm{~km})$ off FNPP in October 2012 revealed that radioactive Cs concentration in the 
uppermost sediment layer were higher south of FNPP, though high activity concentration patches were also observed at a few sites north of FNPP [42]. Therefore, recruitment of their larvae could have been expected from remote areas to sites near FNPP. Nevertheless, data in the present study revealed that neither juvenile nor adult $T$. clavigera were observed at Ottozawa (Okuma), approximately $1 \mathrm{~km}$ south of FNPP, until at least 2016; thus, for invertebrates including sessile organisms in the intertidal zone near FNPP, some environmental factors seem to have inhibited reproduction, recruitment, or both.

Among the factors that might have inhibited recovery of invertebrates are strong waves; sustainability or suitability of substrate (e.g., tetrapods or similar concrete structures set along the coast for wave protection) for larvae to settle on; harmful substances such as radionuclides; heavy metals; turbidity or suspended material; insufficient amounts of prey organisms; and excess of predators. Before the FNPP accident, there were strong waves, substrate (e.g., tetrapods or similar concrete structures set along the coast for wave protection) for larvae to settle on, and various kinds of intertidal predator and prey invertebrates in the coastal waters off Fukushima Prefecture, similar to those after the FNPP accident. Although the possibility of changes in predators or prey affecting invertebrate populations cannot be ruled out, strong waves and substrate are unlikely to be those that inhibited reproduction or recruitment of invertebrates including sessile organisms in the intertidal zone near FNPP. Regarding the possible impacts by harmful substances, such as radionuclides, heavy metals and turbidity or suspended material, we need to carefully examine the effect of construction to cover the radionuclide-contaminated bottom sediments of the FNPP port; this construction was conducted between March 2012 and April 2015 [43, 44]. Approximately 33,000 $\mathrm{m}^{3}$ of bentonite and cement were used for the construction from March 14 to July 5, 2012 [43]. Another approximately $32,500 \mathrm{~m}^{3}$ of bentonite, sand, and cement were also used for the construction from July 17, 2014 to April 23, 2015 [44]. Cement is known to include several heavy metals, and the specific gravity of cement is $3050 \mathrm{~kg} / \mathrm{m}^{3}$ [45]. We tried to estimate the total amount of heavy metals, which had been deposited into the marine environment during the construction. Assuming that the half of total amount of material (i.e., bentonite, sand and cement) used for the construction was cement, then the total weight of cement used for construction to cover the radionuclidecontaminated bottom sediments of the FNPP port was approximately 100,000 metric tons. This cement included various amounts of chromium $(\mathrm{Cr})$, copper $(\mathrm{Cu})$, zinc $(\mathrm{Zn})$ and lead $(\mathrm{Pb})$ and other heavy metals, which were intentionally deposited into the marine environment adjacent to FNPP; consequently, the coastal waters of Fukushima Prefecture, especially close to FNPP, might have been contaminated (Table 6.4). Thus, these heavy metals, as well as turbidity or suspended material from the construction activity, may have had ecological effects (i.e., adverse effects on larval, juvenile, and adult invertebrates in the intertidal zone) that should be elucidated in the near future. Similar impacts on the number of species and population densities by the restoration work of coastal structures were also likely at Tomioka Fishing Port (Tomioka) (since 2015), Urajiri (since 2013) and Ishinomaki (since 2012) [46-48]. The lack of observed egg capsules spawned by rock shells at Urajiri 
Table 6.4 General composition of heavy metals in cement and their estimated total amounts used in the construction to cover the radionuclide-contaminated bottom sediments of the FNPP port from March 2012 to April 2015

\begin{tabular}{l|l|l}
\hline Metals & Composition $(\mathrm{mg} / \mathrm{kg})$ & Estimated total amount $(\mathrm{t})$ \\
\hline Total $\mathrm{Cr}$ & 98 & 9.8 \\
\hline $\mathrm{Hexavalent} \mathrm{Cr}$ & 10.8 & 1.1 \\
\hline $\mathrm{Cu}$ & 140 & 14.0 \\
\hline $\mathrm{Zn}$ & 511 & 51.0 \\
\hline $\mathrm{As}$ & 18.9 & 1.9 \\
\hline $\mathrm{Se}$ & $<1$ & $<0.1$ \\
\hline $\mathrm{Cd}$ & 2.0 & 0.2 \\
\hline Total $\mathrm{Hg}$ & 0.023 & 0.002 \\
\hline $\mathrm{Pb}$ & 111 & 11.1 \\
\hline
\end{tabular}

General composition of metals as reported by [45]. We estimated the total amount of cement used for the construction to be approximately 100,000 metric tons, assuming that cement comprised half of the total amount of material (i.e., bentonite, sand and cement) used

in 2015 (Table 6.3) might also have been associated with the restoration of coastal structures.

There have been many scientific researches and review papers on the toxicities of heavy metals to marine and estuarine organisms [49-54]. Although it is known that the toxicities of heavy metals to marine and estuarine organisms can vary according to their chemical speciation (e.g., free ions are more toxic than other chemical species) and $\mathrm{pH}[50,53,54]$, the embryos and larvae of marine or estuarine invertebrates are generally sensitive to heavy metals: for example, $\mathrm{LC}_{50}$ values (the concentrations at which $50 \%$ of the tested organisms die) for the embryos of American oyster (Crassostrea virginica) were $5.6 \mathrm{ppb}(\mu \mathrm{g} / \mathrm{L}), 5.8 \mathrm{ppb}(\mu \mathrm{g} / \mathrm{L})$, and $103 \mathrm{ppb}(\mu \mathrm{g} / \mathrm{L})$ for mercury $(\mathrm{Hg})$, silver $(\mathrm{Ag})$ and $\mathrm{Cu}$, respectively. $\mathrm{LC}_{50}$ values for nickel $(\mathrm{Ni}), \mathrm{Pb}$ and cadmium $(\mathrm{Cd})$ were $1.18 \mathrm{ppm}(\mathrm{mg} / \mathrm{L}), 2.45 \mathrm{ppm}(\mathrm{mg} / \mathrm{L})$, and $3.80 \mathrm{ppm}(\mathrm{mg} / \mathrm{L})$, respectively [52]. Moreover, in the presence of multiple metals, the toxicities are reported to be additive; the presence of multiple metals may be more realistic than the presence of single metals in marine/estuarine environments [54].

The effect of turbidity and suspended material in aquatic environments has been well studied (e.g., Stern and Stickle [55]). Most studies on adult estuarine and marine bivalves (clams, oysters, and mussels) have indicated that the mortality rate among populations adjacent to dredging and disposal areas is low, except for individuals directly buried by the disposal operation; however, the percentage occurrence of normally developing eggs and larvae may decrease as the concentration of suspended solids increases in the range of concentrations normally resulting from dredging and disposal [55]. Thus, further experimental studies are necessary to elucidate the effect of construction to cover the radionuclide-contaminated bottom sediments of the FNPP port, as well as other restoration work of coastal structures.

The exposure situation for intertidal organisms in Fukushima Prefecture could be complex with many aspects, including various potential direct impacts such as physical harm from the tsunami, and toxicity from chemicals and radionuclides in 
the massive release immediately after the accident, potentially leading to acute effects [34]. Thereafter, there could have been continued releases to the sea of radionuclides and other harmful substances (i.e., heavy metals and turbidity or suspended material from the construction to cover the radionuclide-contaminated bottom sediments of the FNPP port); these releases could have had ecological effects, for example, on interspecific relationships (such as predator-prey relationships or competition for prey organisms and habitat). The effect could also have involved intraspecific relationships (competition for prey organisms, habitat and mating partners) [56-58].

At much higher dose rates, possibly immediately after the accident, differences among taxa in sensitivity to radiation could create competitive advantages for resistant organisms within a taxon and between populations of interacting taxa $[23,59]$. Thus, in addition to differences in the direct radiosensitivity of individual organisms, life history traits including responses to changes in resources and generation times affect the consequences of radiation exposure. Exposures to radiation may have been high during or shortly after the accident [56]. In addition, note that particularly at lower doses, ecological factors and variability can be more important than direct radiation effects; therefore, a different conceptual methodology may be necessary to assess ecosystem-level effects, possibly including site-specific assessment of the effect of potential disturbances on ecosystems [56].

Further studies are needed to clarify the main causal factors for declining intertidal biota and subsequent slow recovery near FNPP, possibly through determining the acute, subacute and chronic toxicity of various radionuclides, chemicals and other factors in laboratory experiments. Continued field observations of spatiotemporal changes in the populations of sessile organisms near FNPP, including rock shell populations, are also necessary to evaluate their recovery in the future; these studies should consider the characteristics of habitats that may influence the distribution of sessile organisms. The focus should be on increasing population densities and reproductive success in terms of active behaviors such as mating and egg-laying and the subsequent successful recruitment of larvae and juveniles. Both field and laboratory studies will also be necessary to observe and evaluate possible multigenerational effects such as changes in reproductive success resulting from exposure to low-dose radiation and other environmental stressors.

\subsection{Conclusions}

We conclude that the population densities and species richness of intertidal invertebrates along the coast off Fukushima Prefecture have decreased since March 2011, especially south of FNPP. The recovery from this decline in population densities of intertidal invertebrates, including T. clavigera, as well as in the number of invertebrate species, has been limited and slow at sites located near and south of FNPP; further studies are needed to clarify the main causal factors. 
Acknowledgment Many thanks to the Fukushima Prefectural Government for permission to enter the restricted area around FNPP. Funding was provided by a Grants-in-Aid for Scientific Research (B) to T.H. (\#15H04537) from the Japan Society for the Promotion of Science.

\section{References}

1. Steinhauser G, Brandl A, Johnson TE (2014) Comparison of the Chernobyl and Fukushima nuclear accidents: a review of the environmental impacts. Sci Total Environ 470-471:800-817

2. Tokyo Electric Power Company (2012a) Estimation of the amount of radionuclides emitted from Fukushima Daiichi Nuclear Power Plant accidents to the atmosphere. [in Japanese] Available at: http://www.tepco.co.jp/cc/press/betu12_j/images/120524j0105.pdf. Accessed 21 Mar 2018

3. Tokyo Electric Power Company (2012b) Estimation of the amount of radionuclides emitted from Fukushima Daiichi Nuclear Power Plant accidents to the sea (around the Fukushima Daiichi Nuclear Power Plant exclusive harbour). [in Japanese]. Available at: http://www.tepco. co.jp/cc/press/betu12_j/images/120524j0102.pdf. Accessed 21 Mar 2018

4. Aoyama M, Kajino M, Tanaka TY et al $(2016){ }^{134} \mathrm{Cs}$ and ${ }^{137} \mathrm{Cs}$ in the North Pacific Ocean derived from the March 2011 TEPCO Fukushima Dai-ichi Nuclear Power Plant accident, Japan. Part two: estimation of ${ }^{134} \mathrm{Cs}$ and ${ }^{137} \mathrm{Cs}$ inventories in the North Pacific Ocean. J Oceanogr 72:67-76

5. Estournel C, Bosc E, Bocquet $\mathrm{M}$ et al (2012) Assessment of the amount of cesium-137 released into the Pacific Ocean after the Fukushima accident and analysis of its dispersion in Japanese coastal waters. J Geophys Res 117:C11014

6. Kawamura H, Kobayashi T, Furuno A et al (2011) Preliminary numerical experiments on oceanic dispersion of ${ }^{131} \mathrm{I}$ and ${ }^{137} \mathrm{Cs}$ discharged into the ocean because of the Fukushima Daiichi nuclear power plant disaster. J Nucl Sci Technol 48:1349-1356

7. Kobayashi T, Nagai H, Chino M et al (2013) Source term estimation of atmospheric release due to the Fukushima Dai-Ichi nuclear power plant accident by atmospheric and oceanic dispersion simulations. J Nucl Sci Technol 50:255-264

8. Smith G (2014) Sources, effects and risks of ionizing radiation. UNSCEAR 2013 report. Volume I: report to the general assembly, annex A: levels and effects of radiation exposure due to the nuclear accident after the 2011 Great East-Japan earthquake and tsunami. J Radiol Prot Off J Soc Radiol Prot 34:725

9. Charette MA, Breier CF, Henderson PB et al (2013) Radium-based estimates of cesium isotope transport and total direct ocean discharges from the Fukushima nuclear power plant accident. Biogeosciences 10:2159-2167

10. Miyazawa Y, Masumoto Y, Varlamov SM et al (2013) Inverse estimation of source parameters of oceanic radioactivity dispersion models associated with the Fukushima accident. Biogeosciences 10:2349-2363

11. Rypina II, Jayne SR, Yoshida S et al (2013) Short-term dispersal of Fukushima-derived radionuclides off Japan: modeling efforts and model-data intercomparison. Biogeosciences 10:4973-4990

12. Tsumune D, Tsubono T, Aoyama $\mathrm{M}$ et al (2012) Distribution of oceanic ${ }^{137} \mathrm{Cs}$ from the Fukushima Daiichi nuclear power plant simulated numerically by a regional ocean model. J Environ Radioact 111:100-108

13. Tsumune D, Tsubono T, Aoyama M et al (2013) One-year, regional-scale simulation of $137 \mathrm{Cs}$ radioactivity in the ocean following the Fukushima Daiichi nuclear power plant accident. Biogeosciences 10:5601-5617

14. Buesseler K, Dai M, Aoyama M et al (2017) Fukushima Daiichi-derived radionuclides in the ocean: transport, fate, and impacts. Annu Rev Mar Sci 9:173-203 
15. Fisheries Agency of Japan (2018) Results of the monitoring on radioactivity level in fisheries products. Available at http://www.jfa.maff.go.jp/e/inspection/index.html. Accessed $21 \mathrm{Mar}$ 2018

16. Wada T, Nemoto Y, Shimamura S et al (2013) Effects of the nuclear disaster on marine products in Fukushima. J Environ Radioact 124:246-254

17. Wada T, Fujita T, Nemoto $Y$ et al (2016) Effects of the nuclear disaster on marine products in Fukushima: an update after five years. J Environ Radioact 164:312-324

18. International Commission on Radiological Protection (2008) Environmental protection - the concept and use of reference animals and plants. ICRP Publication 108. Ann ICRP 38:4-6. (ICRP, 2008)

19. Vandenhove H (2011) Effects of ionizing radiation on non-human biota. Available at: http:// www.bvsabr.be/15april2011/Vandenhove.pdf. Accessed 30 June 2015

20. United Nations Scientific Committee on the Effects of Atomic Radiation (1996) Sources and effects of ionizing radiation, UNSCEAR Report to the General Assembly, with Scientific Annex: effects of radiation on the environment. United Nations sales publication E.96.IX.3 (United Nations, 1996)

21. United Nations Scientific Committee on the Effects of Atomic Radiation (2008) Sources and effects of ionizing radiation. UNSCEAR Report to the General Assembly, with Scientific Annexes, Annex E: effects of ionizing radiation on non-human biota. (United Nations, 2008)

22. United Nations Scientific Committee on the Effects of Atomic Radiation (2011) Sources and effects of ionizing radiation. Volume II: effects, Scientific Annexes C, D and E. United Nations Scientific Committee on the Effects of Atomic Radiation sales publication E.11.IX.3 (United Nations, 2011)

23. Copplestone D, Hingston JL, Real A (2008) The development and purpose of the FREDERICA radiation effects database. J Environ Radioact 99:1456-1463

24. FREDERICA radiation effects database. (2006). Available at: http://www.frederica-online. org/mainpage.asp. Accessed 21 Mar 2018

25. Garnier-Laplace J, Copplestone D, Gilbin R et al (2008) Issues and practices in the use of effects data from FREDERICA in the ERICA integrated approach. J Environ Radioact 99:1474-1483

26. Andersson P, Garnier-Laplace J, Beresford NA et al (2009) Protection of the environment from ionising radiation in a regulatory context (PROTECT): proposed numerical benchmark values. J Environ Radioact 100:1100-1108

27. Beresford NA, Brown J, Copplestone D et al. (2007) D-ERICA: an integrated approach to the assessment and management of environmental risks from ionising radiation. ERICA project (FI6R-CT-2004-508847, 2007). Available at: https://wiki.ceh.ac.uk/download/ attachments/115017395/D-Erica.pdf. Accessed 21 Mar 2018

28. Miura O, Kanaya G (2017) Impact of the 2011 Tohoku earthquake tsunami on marine and coastal organisms. Biol Int S36:81-92

29. Urabe J, Suzuki T, Nishita T et al (2013) Immediate ecological impacts of the 2011 Tohoku earthquake tsunami on intertidal flat communities. PLoS One. https://doi.org/10.1371/journal. pone.0062779

30. Hidaka M, Wakui K, Kamiyama K et al (2012) Change in sediment characters and bathymetry in Matsukawaura Inlet due to the tsunami on March 11, 2011. J Jpn Soc Civ Eng, B3 (Hydraul, Coast Environ Eng) 68:I_186-I_191. [in Japanese]

31. Fukushima Prefectural Government (2015a) Surveys on the environment and aquatic organisms in Matsukawaura, Fukushima. http://www.pref.fukushima.lg.jp/uploaded/attachment/141950. pdf [in Japanese]

32. Seike K, Shirai K, Kogure Y (2013) Disturbance of shallow marine soft-bottom environments and megabenthos assemblages by a huge tsunami induced by the 2011 M9.0 Tohoku-Oki earthquake. PLoS One. https://doi.org/10.1371/journal.pone.0065417

33. Takami H, Won NI, Kawamura T (2012) 5. Ontogenetic habitat shift in ezo abalone Haliotis discus hannai. Nippon Suisan Gakkaishi 78:1213-1216. in Japanese 
34. Horiguchi T, Yoshii H, Mizuno S et al (2016) Decline in intertidal biota after the 2011 Great East Japan earthquake and tsunami and the Fukushima nuclear disaster: field observations. Sci Rep 6:20416. https://doi.org/10.1038/srep20416

35. Clarke KR (1993) Non-parametric multivariate analyses of changes in community structure. Australian J Ecol 18:117-143

36. Clarke KR, Warwich RM (2001) Change in marine communities: an approach to statistical analysis and interpretation, 2nd edn. PRIMER-E, Plymouth

37. Tokyo Electric Power Company (2001) Marine organisms. In: Environmental impact assessment, regarding the construction of Units 7 and 8 of the Fukushima Daiichi Nuclear Power Plant, 5.11-1-5.11-14 (TEPCO, 2001). [in Japanese]

38. Nakano D, Nagoshi M (1980) Growth and age of Thais clavigera (Küster), Prosobranch, in tidal zone around Shima Peninsula, Japan. 25th anniversary memorial Journal for Toba Aquarium, 87-92. [in Japanese]

39. Kubota M, Nakata K, Nakamura Y (1981) Continental shelf waves off the Fukushima coast part I: observations. J Oceanogr Soc Jpn 37:267-278

40. Kaeriyama H (2017) Oceanic dispersion of Fukushima-derived radioactive cesium: a review. Fish Oceanogr 26:99-113

41. Yasuda I (2003) Hydrographic structure and variability in the Kuroshio-Oyashio transition area. J Oceanogr 59:389-402

42. Horiguchi T, Kodama K, Aramaki T et al. (2018) Radiocesium in seawater, sediments, and marine megabenthic species in coastal waters off Fukushima in 2012-2016, after the 2011 nuclear disaster. Mar Environ Res, in press

43. Tokyo Electric Power Company (2012c) Construction to cover the bottom sediments of FNPP specific port (as of July 18, 2012). [in Japanese]. Available at: http://www.tepco.co.jp/nu/fukushima-np/images/handouts_120718_02-j.pdf. Accessed 21 Mar 2018

44. Tokyo Electric Power Company (2015) Construction to cover the bottom sediments of FNPP specific port (as of April 23, 2015). [in Japanese]. Available at: http://www.tepco.co.jp/nu/ fukushima-np/handouts/2015/images/handouts_150423_02-j.pdf. Accessed 21 Mar 2018

45. Ugajin $\mathrm{T}$ (2001) The effects of the trace elements in cement on the environment. Concr J 39:14-19. [in Japanese]

46. Fukushima Prefectural Government (2015b) Reconstruction of Tomioka Fishing port (as of September 24, 2015). [in Japanese]. Available at: https://www.pref.fukushima.lg.jp/ sec/41390a/tomioka-kaigan.html. Accessed 21 Mar 2018

47. Reconstruction Agency (2015a) Activities plan for reconstruction of Minami-Soma City, Fukushima Prefecture. (as of July 31, 2015). [in Japanese]. Available at: http://www.reconstruction.go.jp/topics/main-cat1/sub-cat1-3/20150731/20150731_Fukushima03Minamisoma. pdf. Accessed 21 Mar 2018

48. Reconstruction Agency (2015b) Activities plan for reconstruction of Ishinomaki City, Miyagi Prefecture. (as of July 31, 2015). [in Japanese]. Available at: http://www.reconstruction.go.jp/ topics/main-cat1/sub-cat1-3/20150731/20150731_Miyagi03Ishinomaki.pdf. Accessed 21 Mar 2018

49. Ansari TM, Marr IL, Tariq N (2004) Heavy metals in marine pollution perspective-a mini review. J Appl Sci 4:1-20

50. Bryan GW (1971) The effects of heavy metals (other than mercury) on marine and estuarine organisms. Proc R Soc Lond B Biol Sci 177:389-410. https://doi.org/10.1098/rspb.1971.0037

51. Bryan GW, Langston WJ (1992) Bioavailability, accumulation and effects of heavy metals in sediments with special reference to United Kingdom estuaries: a review. Environ Pollut 76:89-131

52. Calabrese A, Collier S, Nelson DA et al (1973) The toxicity of heavy metals to embryos of the American oyster Crassostrea virginica. Mar Biol 18:162-166

53. Rainbow PS (1985) The biology of heavy metals in the sea. Int J Environ Stud 25:195-211. https://doi.org/10.1080/00207238508710225 
54. Verslycke T, Vangheluwe M, Heijerick D et al (2003) The toxicity of metal mixtures to the estuarine mysid Neomysis integer (Crustacea: Mysidacea) under changing salinity. Aquat Toxicol 64:307-315

55. Stern EM, Stickle WB (1978) Effects of turbidity and suspended material in aquatic environments: literature review, Technical Report D-78-21 (Dredged Material Research Program) 117 p. U. S. Army Engineer Waterways Experiment Station, Vicksburg

56. Bradshaw C, Kapustka L, Barnthouse L et al (2014) Using an ecosystem approach to complement protection schemes based on organism-level endpoints. J Environ Radioact 136:98-104

57. Bréchignac F, Bradshaw C, Carroll S et al (2011) Recommendations from the international union of radioecology to improve guidance on radiation protection. Integr Environ Assess Manag 7:411-413

58. International Union of Radioecology (2013) Towards an ecosystem approach for environment protection with emphasis on radiological hazards. IUR Report no.7 - 2nd edn. (9780-9554994-4-9, 2012). Available at: www.iur-uir.org/en/publications/others-publications/ id-15-iur-report-7-towards-an-ecosystem-approach-for-environment-protection-with-emphasis-on-radiological-hazards. Accessed 21 Mar 2018

59. Whicker WF, Schultz V (1982) Radioecology: nuclear energy and the environment, vol 1. CRC Press, Boca Raton, p 212

Open Access This chapter is licensed under the terms of the Creative Commons Attribution 4.0 International License (http://creativecommons.org/licenses/by/4.0/), which permits use, sharing, adaptation, distribution and reproduction in any medium or format, as long as you give appropriate credit to the original author(s) and the source, provide a link to the Creative Commons license and indicate if changes were made.

The images or other third party material in this chapter are included in the chapter's Creative Commons license, unless indicated otherwise in a credit line to the material. If material is not included in the chapter's Creative Commons license and your intended use is not permitted by statutory regulation or exceeds the permitted use, you will need to obtain permission directly from the copyright holder.

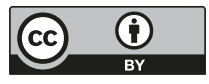

